\title{
The 2010 HMGs Ten Years Later: Where Do We Go From Here?
}

\author{
Steven C. Salop ${ }^{1} \cdot$ Fiona Scott Morton ${ }^{2}$
}

Accepted: 25 December 2020 / Published online: 9 January 2021

(C) The Author(s), under exclusive licence to Springer Science+Business Media, LLC part of Springer Nature 2021

\begin{abstract}
In this article, which is part of the Symposium on the Tenth Anniversary of the 2010 Horizontal Merger Guidelines, we suggest a number of improvements that should be considered in the next revision of the Guidelines. Our analysis is based on the observation that horizontal merger policy has suffered from under-enforcement. We provide evidence that the enforcement agencies face significant resource constraints that require a triage process that inevitably leads to under-enforcement. In light of merger law placing greater weight on avoiding false negatives and under-deterrence than false positive and over-deterrence, the article suggests a number of ways in which the under-enforcement bias might be corrected, including (among others): rolling back the increase in the HHI "red zone" thresholds; mandating anticompetitive presumptions for mergers with high GUPPIs, acquisitions of mavericks, and acquisitions by dominant firms; closer analysis of common ownership by financial funds; and expanded analysis of potential competition mergers.
\end{abstract}

Keywords Mergers · Antitrust - Quantitative evidence · Concentration · Enforcement

\section{Introduction}

The 2010 Horizontal Merger Guidelines (HMGs) were cast as an evolutionary step beyond the 1992 HMGs and the 2006 Merger Commentary. In this article, we suggest further improvements that should be considered in the next revision of the HMGs. Our analysis is based on the observation that horizontal merger policy has suffered from under-enforcement and false negatives.

Steven C. Salop

salop@law.georgetown.edu

1 Georgetown University Law Center, Washington, DC, USA

2 Yale University School of Management, New Haven, CT, USA 
Over the last 50 years, "Chicago School" thought has worked to persuade courts that "false negatives" (i.e., under-deterrence and insufficient interdiction of anticompetitive mergers) are less harmful to consumer welfare than are "false positives" (i.e., over-deterrence and excessive interdiction of potentially procompetitive mergers). The goal of antitrust law, including merger law, is consumer welfare. In the case of mergers among competing sellers, this corresponds to consumer surplus, not total surplus. This goal is reflected in the HMGs' requirement that merger-specific cost savings must be sufficient to deter price increases. However, the legal standard for mergers is "may be substantially to lessen competition." Interpreting the statute to mean the probability of a merger substantially lessening competition must exceed $50 \%$ would be significantly stricter than what U.S. courts actually do. It is not necessary to show such a high probability of the merger's substantially lessening competition. Instead, the standard requires only an "appreciable risk" or a "reasonable probability" that competition will be reduced. ${ }^{1}$ This point is recognized in Sect. 1 of 2010 HMGs, which state that the Guidelines "reflect the congressional intent that merger enforcement should interdict competitive problems in their incipiency and that certainty about anticompetitive effect is seldom possible and not required for a merger to be illegal."

Greater weight on false negatives is reflected in the longstanding legal standard that mergers that create a significant market share in a concentrated market are legally presumed to be anticompetitive, and the burden is placed on the merging parties to rebut that presumption. This presumption is analogous to a Bayesian prior. If the presumption is triggered, the burden is placed on the merging parties to offer rebuttal evidence. Thus, the default legal standard is to enjoin such mergers-absent evidence that either undermines the market share and concentration evidence or provides a procompetitive justification. This standard is important because the HMGs are intended to be consistent with a merger law that is not premised on the Pareto principle, total surplus, or an overarching focus on preventing false positives.

In short, a default enforcement rule of "do nothing if the agency is unsure what will happen in the future" is clearly inapplicable to a merger enforcement policy that is designed to protect consumer surplus, as well as the wording of the statute itself. Not enforcing is an active choice that can harm consumers. ${ }^{2}$

There also is evidence that the enforcement agencies face significant resource constraints that require triage that inevitably leads to under-enforcement. The number of transactions that can be effectively investigated or litigated is limited. The

\footnotetext{
1 A standard that is based solely on the probability of consumer harm does not properly account for the level of expected harm if the harms of false positives and false negatives are unequal. Thus, a $50+\%$ standard would under-enforce if the harm from a false negative exceeds the harm from a false positive.

2 If determination of competitive effects were fairly obvious, the choice of default might not matter. But the likely effects are not obvious: If they were, firms would not spend \$15-25 million going through a "second request" (or \$10-20 million more on a preliminary injunction hearing), if the required divestiture or the need to abandon or restructure the deal was so obvious at an earlier point. Nor would merger retrospectives reveal significant false negatives.
} 
agencies have resources to investigate only those mergers that suggest the most serious concerns, not all the mergers that raise real concerns. Constraints on the number of cases that can be litigated inevitably force the agencies to accept weaker-thanoptimal consent decrees or even to clear mergers that deserve to be remedied or enjoined. Triage also naturally leads to under-deterrence. ${ }^{3}$ Triage further suggests to courts that the standard for illegal effects is much higher than it actually is, since the selection of cases that go to trial are disproportionately harmful.

We have not seen evidence that is sufficient to reject this hypothesis. Consider the following:

- Agency budgets have not kept pace with the number of reported mergers. One would expect that more transactions would also involve more deals that raise potential concerns. Table 1 reports agency budgets for the 2010-2018 period, relative to the number and value of merger transactions. The BRM Index gauges the decline since 2010 in the agency enforcement budgets relative to the number of merger transactions. The BMV Index gauges the decline relative to the $\mathrm{dol}$ lar value of M\&A transactions. ${ }^{4}$ Table 1 shows that budgets have declined by approximately $30 \%$ since 2011, relative to M\&A activity. We also suspect that agency costs of second request investigations and litigation also have increased over time as the role of quantification has increased.

- The number of agency "second requests" for additional information is much more stable than is the number of reported mergers that might warrant intensive investigation. Table 2 shows that the number of second requests has ranged between 42 and 55 in 2010-2018, while the number of transactions ranged from less than 1300 to more than $2000 .^{5}$ This is consistent with the number of second requests' being limited by resource constraints and some problematical mergers' being cleared.

\footnotetext{
${ }^{3}$ This is the reverse of the proverbial Texas Ranger with just one bullet, but who can deter a crowd because no one wants to take the risk of rushing him first. But the Ranger fails to deter when all the members of the crowd move at the same time. (Kleiman and Kilmer 2009).

${ }^{4}$ We use the DOJ budget for the Antitrust Division. U.S. Dep't of Justice (2020), Appropriation Figures for the Antitrust Division Fiscal Years 1903-2021. Retrieved from https://www.justice.gov/atr/appro priation-figures-antitrust-division. However, our data for the FTC budget includes its consumer protection mission. Fed. Trade Comm'n (2020). FTC Appropriation and Full-Time Equivalent (FTE) History. Retrieved from https://www.ftc.gov/about-ftc/bureaus-offices/office-executive-director/financial-manag ement-office/ftc-appropriation. The enforcement budget for any given year is a sum of those two figures. The adjusted number of mergers that are reported -- transactions for which a second request could have been issued -- comes from Fed. Trade Comm'n \& U.S. Dep't of Justice (2019, p. 22 \& n.2). Hart-ScottRodino Annual Report Fiscal Year. Retrieved from https:/www.ftc.gov/system/files/documents/reports/ federal-trade-commission-bureau-competition-department-justice-antitrust-division-hart-scott-rodino/ fy18hsrreport.pdf. The M\&A value data come from the Institute for Mergers, Acquisitions and Alliances. IMAA (2020). Announced M\&A in the United States by Numbers and Value by Years. Retrieved from, https://imaa-institute.org/m-and-a-us-united-states/.

5 Fed. Trade Comm'n \& U.S. Dep't of Justice (2019 p. 22 \& n.2), Hart-Scott-Rodino Annual Report. Retrieved from https://www.ftc.gov/system/files/documents/reports/federal-trade-commission-bureaucompetition-department-justice-antitrust-division-hart-scott-rodino/fy $18 \mathrm{hsrreport}$.pdf.
} 
- Table 2 also reports that a very high percentage of the deals that get a second request are challenged. This suggests that only the very most troublesome mergers are investigated. This data also is consistent with some problematical deals falling through the cracks. Indeed, most merger lawyers (who lack "Stockholm Syndrome") have experienced surprise at deals that escaped without a challenge, or sometimes even without a second request.

- The agencies have a very high win rate in litigated cases. In the 2012-2018 period, in cases where the agencies filed a complaint without an accompanying consent decree, the agencies prevailed in more than 35 cases: by winning in court; by obtaining a later settlement; or by the parties' abandoning the transaction. The merging parties have prevailed in court in only three cases. One loss was a "potential competition" merger, ${ }^{6}$ and one was a vertical merger, ${ }^{7}$ where the law is less favorable to challenges. ${ }^{8}$ This high win rate is consistent with both limited deterrence and risk-averse agencies that threaten to take only the most egregious cases to court. A rough estimate is that the alleged post-merger HHIs in cases that have gone to trial for the past two decades have averaged above 5000, with average delta HHIs exceeding $1500 .^{9}$

- The high stakes of the merging parties yield incentives for them to spend considerable legal and economic resources in criticizing and rebutting the agencies' quantitative evidence and presenting their own additional econometrics. The agencies must do more to keep up, but resource constraints limit their ability. The combination of high stakes for the merging parties and agency resource constraints also suggests that the false positive rate would be low. The parties have incentives to fight very hard to justify their deal-regardless of whether the value of the deal flows from efficiencies or from market power.

Econometric evidence is consistent with consolidation's leading to market power. ${ }^{10}$ Economists have carried out a number of retrospective analyses of mergers that show that a number of significant mergers have led to reduced competition even when there are consent decrees. Kwoka (2014) retrospectively reviewed mergers

\footnotetext{
${ }^{6}$ FTC v. Steris Corp., 133 F. Supp. 3d 962 (N.D. Ohio 2015).

7 United States v. AT\&T, Inc., 916 F.3d 1029 (D.D.C. 2019).

8 The agencies lost two cases that were filed in 2019: One was litigated as horizontal but was as much a vertical deal: United States v. Sabre Corp., No. 19-1548-LPS, 2020 U.S. Dist. LEXIS 64637 (D. Del. Apr. 7, 2020). The other was a straight horizontal merger case: Federal Trade Commission v. RAG-Stiftung et. al., No. 19-2337, 2020 U.S. Dist. LEXIS 18346 (D.D.C. Feb. 3, 2020). The data on wins has not yet been reported.

9 Authors' calculations.

10 Scott-Morton (2019) and the Joint Response to the House Judiciary Committee on the State of Antitrust Law and Implications for Protecting Competition in Digital Markets separate mergers from other anticompetitive activity. Baker (2017) and (Baker and Scott-Morton 2019) focus on macroeconomic evidence that demonstrates a grim, economy-wide increase in market power. For macroeconomic evidence on rising profit share, see Barkai (2016) and (Barkai and Benzell 2018). For macroeconomic evidence on the rise at the top end of the markup distribution, see (Gans et al. 2019). For labor evidence on monopsony, including the negative effects of non-competes, see. (Goolsbee and Syverson 2019), (Prager and Schmitt 2019), and (Kreuger and Ashenfelter 2018).
} 
Table 1 Agencies' budget shortfalls (2010-2018) Budget-to-merger indices

\begin{tabular}{llllllllll}
\hline Year & 2010 & 2011 & 2012 & 2013 & 2014 & 2015 & 2016 & 2017 & 2018 \\
\hline BRMI & 126 & $\mathbf{1 0 0}$ & 105 & 110 & 88 & 81 & 83 & 75 & 72 \\
BMVI & 127 & $\mathbf{1 0 0}$ & 130 & 103 & 58 & 52 & 73 & 75 & 67 \\
\hline
\end{tabular}

$B R M I$ Indexed ratio of enforcement budgets to adjusted number of mergers reported $(2011$ Index $=100)$ $B M V I$ Indexed ratio of enforcement budgets to total value of US M\&A transactions $(2011$ Index $=100)$

Table 2
requests were possible (2010-2018)
\begin{tabular}{lrrrrrrrrrr} 
Sear & 2010 & 2011 & 2012 & 2013 & 2014 & 2015 & 2016 & 2017 & 2018 \\
\hline No. of transactions* & 1128 & 1414 & 1400 & 1286 & 1618 & 1754 & 1772 & 1992 & 2028 \\
Second requests & 42 & 55 & 49 & 47 & 51 & 47 & 54 & 51 & 45 \\
Challenged transactions** & 33 & 35 & 43 & 30 & 32 & 42 & 46 & 39 & 38 \\
\hline
\end{tabular}

*Adjusted transactions in which a second request could have been issued**Includes only challenges of unconsummated mergers; challenges are listed in the year of the second request

generally, while (Cutler and Scott-Morton 2013), Dafny et al. (2016) and (Gaynor and Town 2012) reviewed the effect of consolidation in the hospital industry.

In light of this evidence, and our own judgement as observers of merger enforcement, our view is that the competitiveness of the U.S. economy would benefit from stricter merger enforcement. This article sets out a number of proposals that might be considered for the update to the HMGs.

We frame our proposals in light of the three-step burden-shifting approach that is used in merger law: In Step 1, the agencies must present enough evidence of risk of anticompetitive harms in order to shift the burden to the merging parties to produce sufficient rebuttal evidence. The agencies normally satisfy this burden through an anticompetitive "structural presumption," which involves sufficiently high postmerger HHIs and HHI increases or, alternatively, direct evidence. If the parties produce sufficient rebuttal evidence in Step 2, then the burden shifts back to the agencies in Step 3 to persuade the court that the merger will fail the overarching legal standard.

Concerns about false negatives suggest that the required evidence required of the agencies to satisfy their Step 1 case should be lowered, that the rebuttal burden placed on the merging parties in Step 2 be raised, and that the agencies' ultimate burden of persuasion at Step 3 be reduced. These changes would deter more anticompetitive merger proposals and permit the agencies to negotiate stronger settlements. Setting legal presumptions and evidentiary burdens is a legal issue, of course. Senator Klobuchar introduced legislation in 2019 (S307) that would reduce the evidentiary burden on the agencies by replacing the standard from "substantially" lessens competition to "materially" lessens competition, where "materially" is defined to mean "more than a de minimis amount." It also would mandate a substantial rebuttal burden for certain large horizontal mergers, whereby the firms would be 
required to show that their deal would not materially harm competition-in contrast to current law, where the burden is placed on the government.

Absent legislation, the agencies can change enforcement policies but not the legal burdens in court. However, because the courts respect the agencies' expertise, the HMGs could have a role in influencing the law. Thus, we will note some policy changes that will require changes in the law-not simply changes in agency enforcement policy that is reflected in the HMGs.

\section{Suggestions for Revisions in the HMGs}

We next suggest a number of revisions to the HMGs' merger enforcement policy and some desirable legal changes that the HMGs might influence.

\subsection{Adopt an Anticompetitive Presumption Based the GUPPI and Eliminate the GUPPI Safe Harbor}

The 2010 HMGs popularized the use of upward pricing pressure (UPP). They describe in words the Value of Diverted Sales (VDS) and Gross Upward Pricing Pressure Index (GUPPI). They suggest in $\$ 6.1$. that the superiority of these metrics over the HHI for evaluating unilateral effects. ${ }^{11}$ We suggest the HMGs adopt an anticompetitive enforcement presumption that is based on the GUPPI that could meet the agency's initial burden even if the HHI thresholds for the structural presumption are not. While not law, this would be a first step to a legal presumption since the HMGs are designed to influence (i.e., "assist") the law.

A GUPPI anticompetitive presumption would not be difficult to formulate. (Salop and Moresi 2009) demonstrates that if the simple GUPPIs for both merging firms are at least $10 \%$, then the merging firms by themselves would more than satisfy the hypothetical monopolist test for a separate market, if demand is linear and the SSNIP threshold is $5 \% .{ }^{12}$ This enforcement presumption would be rebuttable but should incorporate a sliding scale.

This analysis suggests that if the GUPPIs both exceed $10 \%$, then the agencies should define the market as comprised solely of the two merging firms, in which case the HHI would equal 10,000. While this is a possible approach, we do not think that it is necessary and may not be advisable. First, the HMGs have a proviso that they will include in the market a firm $\mathrm{C}$ that is a closer substitute to the either of

\footnotetext{
11 This remark might be read by a laissez-faire oriented court as recommending abandonment or weakening of the HHI anticompetitive presumption for complaints that allege unilateral effects. Since the structural presumption is useful for reducing false negatives by resource-constrained agencies, that language would be worth revising.

12 Take for example a simultaneous GUPPI with uniform price increases, where GUPPIu=DR $x \mathrm{M} /$ $(1-D R)=20 \%$. With linear demand, the profit-maximizing price increase is $G U P P I u / 2=10 \%$. As is noted in the 2010 HMGs' Example 6, limiting the market definition solely to these two firms might not satisfy the additional test in the HMGs that the market must include products that are closer substitutes to either of the two merging firms than they are to each other.
} 
the 2 merging firms than they are to each other. Second, the $10 \%$ threshold is based on linear demand. If demand is not linear a different threshold would be called for. Third, the agency also may fear that the GUPPI evidence might be attacked. Finally, and most important, the agencies often choose to define a market that is not the narrowest possible market for good reason. They may correctly fear that the court will balk at a very narrow market that violates its intuition or will attack the market definition as a gerrymandered submarket. Given the risk, the agencies may decide that they can effectively argue for a unilateral effect even in the context of a broader market.

In retrospect, the failure to adopt a GUPPI anticompetitive presumption likely made sense because GUPPIs were still considered novel. However, this is no longer the case. The HMGs did suggest a quasi-safe harbor for "low" values of simple GUPPIs, where "low" was subsequently defined as $5 \% .{ }^{13}$ In retrospect, this may have been a mistake. The HMGs appear to be premised on the assumption that every merger will lead to significant merger-specific efficiencies and that an "efficiency credit" should be used to set the GUPPI safe harbor. By contrast, (Rose and Sallet 2020) and others have accumulated evidence that most mergers do not produce significant merger-specific efficiencies. This suggests that the GUPPI safe harbor might be deleted entirely. It also suggests that a lower anticompetitive threshold might be adopted. $^{14}$

\subsection{Lower the "Red Zone" HHI Thresholds}

The 2010 HMGs raised the HHI threshold ("red zone") for applying the anticompetitive presumption from a level of 1800 and a change of 100 (or, "1800/100") to a level of 2500 and a change in 200 (or, “2500/200”). In retrospect, this may have been an unfortunate choice.

First, it is not clear why the HHI thresholds were increased, particularly since one goal of the HMGs was to reduce the burden of proof for establishing coordinated effects. One possible explanation is that there has been a major shift in emphasis in merger analysis away from coordinated effects to unilateral effects. ${ }^{15}$ This shift to unilateral may have led to economists having a reduced interest in the HHIs and the

\footnotetext{
132010 HMGs $\$ 6.1$ (text at n.11). In a subsequent speech when he was still the DOJ Economics Deputy AAG, Carl Shapiro suggested that "low" meant 5\%. Shapiro, Carl "Update from the Antitrust Division" (speech at 24, Washington, DC, November 18, 2018). Retrieved from https://www.justice.gov/atr/ file/518246/download.

14 Note that simultaneous GUPPIs are higher than simple GUPPIs (Hausman et al. 2011). In the HMGs Example 5, the simple GUPPI for each firm is GUPPI $=$ DR $\times$ M, where the diversion ratio DR $=33 \%$ and the percentage margin $\mathrm{M}=40 \%$, so that GUPPI $=13.2 \%$. If the diversion ratios between symmetric merging parties are both $33 \%$, then simple GUPPIs of $13 \%$ translates into a simultaneous GUPPI of $22 \%$ $(=13.2 \% \times 1.67)$.

15 The fraction of FTC "second request" investigations that focused on unilateral effects rose from $16 \%$ in fiscal years 1989-1992, to more than half in 1999-2000, and to 76\% in 2011-2014. These figures do not include alleged mergers to monopoly (Coate and Ulrick 2019, pp. 2-3).
} 
red zone thresholds because the HHI level is not relevant for the determination of competitive effects in the typical unilateral effects models.

However, it is an overstatement to say that the HHI level does not matter. First, in the Cournot model with constant elasticity of demand, the pre-merger HHI equals the product of the weighted-average price-cost margin and the demand elasticity. In their important recent paper, Nocke and Whinston (2020) show that the increase in the HHI is relevant in predicting the critical level of marginal cost savings to prevent consumer harm. They show that consumer harm often outweighs assumed synergy levels even when the delta HHI is less than 100 points. If synergies are assumed to be higher, then the critical delta $\mathrm{HHI}$ is larger. In addition, they show that if there is a small efficiency credit, the critical cost savings to prevent a consumer welfare loss is larger when the HHI level is higher. In light of the skepticism expressed in the HMGs regarding the level of verifiable and merger-specific efficiencies, assuming very low (or de minimis) synergies would be more appropriate in setting enforcement policy.

Moreover, in the current triage environment, lower thresholds would strengthen the agencies' hand in the sliding scale and would improve deterrence and reduce false negatives. Indeed, this enforcement benefit would follow even if the HHI entirely lacked predictive power.

Finally, we are concerned that over time the more permissive red zone based on typical practice will have an unintended adverse side effect of creating a "vicious cycle" that will result in even more permissive agency practice. The vicious cycle could develop as follows: Risk-averse agencies strongly prefer to bring cases where they are highly confident that they will benefit from the "sliding scale," whereby "the more compelling the [government's] prima facie case, the more evidence the defendant must present to rebut it successfully." 16 As noted above, the HHIs in cases that reach trial far exceed the red zone thresholds.

The HMGs are designed to assist the courts, who likely interpret the red zone threshold as the agencies' expert opinion of the point where the anticompetitive legal presumption "should" apply. This is reinforced by the fact that HMGs state the agencies' "enforcement policy," based on their "experience." 17 Thus, by announcing this higher internal threshold, the HMGs communicate to courts that a higher threshold for the structural presumption is warranted.

This dynamic would tend further to weaken enforcement over the longer term. ${ }^{18}$ Even if the effect does not show up explicitly in the relatively small number of court decisions, it can change the behavior of potential merging parties and the agencies. It can lead potential merging parties and their counsel to become more aggressive. It

\footnotetext{
16 United States v. Baker Hughes, Inc., 908 F.2d 981, 991 (D.C. Cir. 1990).

17 HMGs at $\S \S 1,5.3$.

18 We view this as a longer-run trend rather than an effect that necessarily has occurred already, and we lack evidence that this cycle is already underway. Analyzing this hypothesis would require non-public data on the HHIs for mergers that are cleared without a remedy, as well as those that are challenged, and the consent decrees demanded. It also would have to control for the policy goals of the different antitrust administrations as well as exogenous changes, such as the merger wave of the late-1990 s and the Great Recession.
} 
similarly may lead the agencies further to raise their internal litigation threshold out of fear that the sliding scale has shifted somewhat. If more mergers are proposedparticularly more mergers with higher HHIs - the agencies will need to further adjust their triage process, which will cause feedback effects on second requests, consent decrees, and litigation decisions.

These feedback effects necessarily will end up raising the internal red zone level. And, as this information becomes known, the vicious cycle will be further reinforced. In the end, unless budgets are increased accordingly, this vicious cycle will lead to increasingly more false negatives.

\subsection{Improve Analysis of Coordinated Effects}

Unilateral effects dominate merger enforcement, perhaps because those models are more tractable than coordinated effects models. UPP measures and econometricbased simulation models can quantify unilateral effects. By contrast, except where there is a maverick, coordinated effects analysis has been stuck in a process of weighing a checklist of facilitating and complicating market factors.

Section 7.1 of the HMGs attempted to reduce the agencies' burden of proof. However, aside from identifying a maverick, it does not indicate what "signs" of vulnerability are sufficient or the "credible basis" for concern. Nor does it explain what evidence of pre-merger coordination should lead to a market definition price benchmark below the prevailing level (Baker and Farrell 2020). This is important because unilateral effects analysis typically assumes that the prevailing price represents a non-cooperative equilibrium.

Analysis of market definition for coordinated effects concerns raises a complexity because it could either lead to prices rising or prices failing to fall. If the prospective merger partners were coordinating their behavior less than perfectly pre-merger, then a post-merger price increase would still be possible. But a concern is also that the merger might prevent price decreases. This is because pre-merger coordination might unravel, whereas the merger will prevent this unraveling. It is to account for this potential pre-merger unraveling possibility that the benchmark price might be set at level below the prevailing price.

There have been some theoretical advances in the analysis of coordination (Harrington 2013; Sabbatini 2016), which we do not have space to review, but more work is needed. The role of the GUPPI or a similar UPP metric in analyzing coordinated effects might be explored in more detail. For example, a unilateral incentive to raise price may increase the likelihood and magnitude of successful coordination, for example, by altering the critical discount rate. There also have been some promising econometric studies that identify past mergers that have created the conditions for coordinated effects to thrive. For example, (Ciliberto and Williams 2014), (Aryal et al. 2018), and (Borenstein and Rose 2014) evaluated coordination in the airline industry. Likewise, in the U.S. beer industry, (Miller and Weinberg 2017) and Miller 
et al. (2019) show that prices abruptly increased after the 2008 consummation of the Miller/Coors merger. They explain these changes with a model of oligopolistic price leadership in which a dominant firm (ABI) publicly announces price changes and competitors follow its lead. ${ }^{19}$ In airlines, multiple horizontal mergers have increased market concentration and exacerbated the problem of tacit collusion. (Ciliberto and Williams 2014) suggest that multimarket contact facilitates airline coordination. They also shows that U.S. legacy carriers communicate strategic intentions in earnings calls to induce market-wide reductions in capacity. In work on cross-ownership, Heim et al. (2019) finds that firms acquire minority shares in actual or potential rivals to stabilize collusive agreements. Even if collusion breaks down, minority shareholding in rival firms helps to soften competition.

The growing potential for algorithmic coordination also suggests greater coordination effects concerns in the future. Algorithmic coordination involves firms' using the combination of Big Data and machine learning to price-coordinate successfully in online retail markets. Early papers suggest that algorithmic coordination is possible, but it would be a complicated endeavor in a world with exogenous shocks (Calvano et al. 2019a, b). However, algorithms likely will improve. If a computer using machine learning can rapidly become a chess grandmaster, then online sellers likely will learn how to coordinate prices successfully.

We encourage economists to complement and monitor the work that no doubt is being done by sellers and business consulting firms. An increased likelihood of algorithmic collusion through machine learning means that coordinated effects will be achievable in more environments. Mergers will tend to increase the likelihood of successful algorithmic coordination by reducing the number of major players. This is another reason why merger policy needs to be tightened.

\subsection{Include Discussion of Common Ownership by Financial Funds}

The literature assessing the competitive effects of common ownership of product market competitors by financial funds is growing rapidly (Boller and Scott-Morton 2020; Azar et al. 2018, 2019; Backus et al. 2018; Backus et al. 2019; Gerakos and Xie 2019; Newham et al. 2018). If the empirical evidence continues to accumulate in a way that raises competitive concerns, the analysis of acquisitions of stock will require greater attention from the agencies. We recommend that the HMGs flag this issue now and discuss how the agency would approach such a case. We further recommend that the agency engage in research-and gathering of relevant information-to help inform future analysis.

\footnotetext{
19 (Miller and Weinberg 2017) also simulates the 2013 ABI/Modelo merger and shows that there would have been lower consumer surplus, absent the divestiture.
} 


\subsection{Adopt an Anticompetitive Presumption for Acquisitions of Maverick Competitors}

The 2010 HMGs comes close to suggesting an anticompetitive presumption if one of the merging firms in a concentrated market has been a maverick competitor. We agree and suggest that this be given more even visibility by making it a formal presumption in $\S 7.1$ and $\S 2.1 .5$. Maverick behavior was a focus of the HRBlock/TaxAct merger case, but the judge raised certain criticisms of the concept because all of the competitors were disruptive. ${ }^{20}$

It would be useful to address those concerns. It also would be useful to consider applying the concept to "killer acquisitions," as defined by Cunningham et al. (2019). ${ }^{21}$ The maverick presumption also might be applied in markets with HHIs below the level where the structural presumption is triggered.

\subsection{Expand Discussion of Post-Merger Competitive Interaction}

Merging parties commonly attempt to rebut the anticompetitive presumption by arguing that intense competition would continue post-merger. However, the HMGs need more discussion of why post-merger competitive interaction among established firms generally would be insufficient to protect consumers. In the Nash/Bertrand differentiated products model, for example, price increases by the merging firms will increase profits in the post-merger game. Moreover, price increases by the merging parties will generally lead to accommodating price increases by non-merging firms. ${ }^{22}$ This "multi-lateral" reinforcing effect is not flagged in the HMGs. ${ }^{23}$ (The HMGs might tend to classify it as a coordinated effect, which also could confuse a court and so should be clarified.)

\subsection{Expand Potential Competition Merger Analysis}

The 2010 HMGs note that the analysis of mergers with potential competitors apply the same basic analysis as for horizontal mergers. However, expansion is warranted. In high tech markets, leading firms commonly make acquisitions of firms that produce complementary (or vertically related) products while they are still potential or nascent. These firms could become significant horizontal competitors over time or partners to competitors of the leading firms. Possible examples include Facebook's acquisition of Instagram and WhatsApp, Google's acquisition of DoubleClick and AdMob, and Amazon's acquisition of Quidsi (the parent of Diapers.com) and Zappos.

\footnotetext{
${ }^{20}$ It also was important in the analysis of the AT\&T'S attempted acquisition of T-Mobile in 2011.

21 Sabre's attempted acquisition of Farelogix may fit the "killer acquisition" model.

22 Repositioning is a possible post-merger mitigating factor, so it would be useful to discuss when the one effect would tend to dominate the other.

23 These issues arise naturally in simulation models. But these effects are relevant even if there is no simulation modeling.
} 
Current law sets an inappropriately high bar that is out of step with the competitive importance of those nascent or potential competitors. The structural presumption does not apply if the target lacks a significant market share and its future share is not sufficiently predictable. The agency must show that the target has a high likelihood of entering a highly concentrated market and having a significant competitive effect. The likelihood prong generally also requires a concrete plan to enter soon. ${ }^{24}$ Potential entrants and nascent competitors may face a risk of failure, which must be examined. The agency also must show that there are not a sufficient number of alternative entrants. If the acquiring firm is not dominant, showing substantial high diversion ratios also might be required (Royall and Di Vincenzo 2010).

These requirements increase the risk of false negatives as the level of uncertainty inherent in all these predictions is high even while the mean effects may be large. A court also erroneously may focus on whether prices would rise above the current level rather than deter future price reductions. The court also may focus on the probability of a competitive effect rather than the expected value of the effect on consumer welfare. ${ }^{25}$ Finally, a common path to entry in many technology markets is that an initially complementary service develops into a substitute, which may be hard for the agencies to map with sufficient certainty to satisfy the current very high bar.

We suggest several changes: First, the agencies might analyze the consumer welfare effects of the various possible paths and predict the expected value impact on consumer welfare, rather than focusing on the probability, and explain the importance of doing so. The expected value impact on consumer welfare often will be negative, even if the probability that the entrant succeeds is significantly less than 50\%. Second, the HMGs might adopt an anticompetitive presumption for leading firm mergers, as discussed next. Economists can help by producing careful retrospectives studies of cleared mergers, particularly when the nascent competitor was alleged not to compete at the time of the transaction. Third, the agencies and the HMGs can explain why such a high bar is not warranted. These proposals accord with those made by (Bush and Massa 2004).

\subsection{Adopt an Anticompetitive Presumption for Leading Firm Mergers}

Enforcement also could be improved if the HMGs applied an anticompetitive presumption to acquisitions of small, nascent, or potential competitors by leading firms and convinced the courts to follow them. This presumption would not be novel. The 1982 HMGs had a strong anticompetitive presumption when the leading firm had a share of at least $35 \%$ and the target had a share of at least $1 \%{ }^{26}$

\footnotetext{
24 E.g., FTC v. Steris Corp., 133 F. Supp. 3d 962 (N.D. Ohio 2015) (According to the FTC, it was only necessary to show that the potential competitor "probably would have entered" the market absent the merger,). By contrast, in its $1984 B A T$ decision, the FTC required "clear proof" that entry would have occurred. In re B.A.T. Industries, 104 F.T.C. 852, 926 (1984).

25 This amounts to failing to balance the consumer welfare effects of false negatives versus false positives.

261982 HMGs at §III.A.2. The 1982 HMGs focused on coordinated effects and formulated the anticompetitive presumption where the post-merger HHI exceeded 1800 and the increase in the HHI exceeded 100. Those Guidelines did not address unilateral effects except with respect to that Leading Firm Proviso.
} 
A strong presumption along these lines would be useful-particularly for digital markets where the "winning" firm is protected by strong network effects. In such markets, the incumbent dominant firm has an incentive to acquire the entrant when it still is nascent, but may grow into a significant competitive threat. The presumption should also apply to vertical or complementary product acquisitions that involve potential or nascent competitors that might grow into horizontal competitors or partners of horizontal competitors.

This approach would require courts to follow the agencies' lead. However, as noted earlier, the courts respect agency expertise, so the HMGs would have an influence. In addition, the HMGs do not exist in a vacuum. The guidance can be supplemented by staff reports and supportive studies by academics. Alternatively, this may be a possible area for new legislation.

\subsection{Clarify the Treatment of Econometric Evidence}

Every year more data become available, and economists naturally apply various econometric and associated simulation modeling to predict the competitive impact of current mergers. The 2010 HMGs encourage the use of these methodologies. ${ }^{27}$

We share the concerns of Kaye (1983), Rubinfeld (1985), and Johnson et al. (2016) that, without clarification, the greater emphasis on econometric evidence will lead to additional false negatives, as will be discussed below, and we have suggestions to mitigate this concern. While we have some specific suggestions, our main point is that current practice is out of date. The agencies should consider the approaches in the literature (and perhaps new research) and adopt an improved statistical standard for merger evidence.

We will focus on the econometric evidence. But before doing so, we note that econometric techniques exist to address only some competitive concerns but not others. Advances in technique often are not chosen because of the importance of the problem to real-world cases, but because the latest statistical advances permit progress in a particular direction. Competitive concerns that lack econometric techniques are no less important to consumer welfare than are others.

For example, part of the reason that coordinated effects concerns have been given less emphasis in recent cases may be that economists have not developed an econometrically intensive measure to predict their prevalence. But if agencies or courts imagine that the lack of an econometric technique is the same thing as the lack of an answer-or a lack of importance-then entire classes of harm will go unenforced. This also could be a reason that innovation concerns are typically given short shrift.

It is useful to begin the discussion of econometric evidence by discussing the agencies' risks of relying on econometric studies to make out their affirmative case in court. First, data sets often are incomplete or contain some errors, and no econometric study is perfect. As a result, it is possible to criticize even a rigorous, well-done study. While agency staff are well-equipped to separate the important

${ }^{27}$ For example, see the HMGs' $\$ 2.1 .2$ (natural experiment evidence) and $§ 6.1$ (simulation models). 
criticisms from the mere debating points, the relative merits of the competing studies and the criticisms must be evaluated in court by a judge who is neither an economist nor a statistician. This makes it difficult for the agency expert economist to explain the study fully and address all of the criticisms that are made by the opposing expert.

Second, the usual econometric practice is to place the burden on whichever side offers the study. For example, suppose a regression would predict that the merger harms consumer welfare if an estimated coefficient is negative and benefits consumer welfare if the estimated coefficient is positive. Suppose the negative impact would be "economically substantial" if the coefficient is equal to (say) -2 , or more negative. Suppose that the regression coefficient estimate is -2.5 , but is not statistically different from zero at a $90 \%$ level of confidence:

If this study were presented to the court by the agency to satisfy its burden of showing consumer harm, the merging parties would argue that the prediction of economically substantial harm be rejected because the null hypothesis of no (or positive) welfare effect cannot be rejected with sufficient confidence. Of course, the agency can make the point that one also could not reject a null hypothesis that the coefficient is -2.5 or even -5 , in which case consumer welfare would be harmed. But this counter may fail because of the mistaken design of the prior: Over-emphasis is commonly placed on whether the zero-value null hypothesis can be rejected.

It is clear that $p$-values do not distinguish true from false claims. ${ }^{28}$ Standard hypothesis testing (as above) focuses on avoiding Type I errors: erroneously rejecting the null hypothesis when it is true. (Thus, this creates a neat correspondence between the Chicago School assumptions and this naïve form of econometrics.) However, Type II errors of erroneously failing to reject the null hypothesis when it is false will have meaningful welfare implications in the type of cases that typically go to trial.

Stated in terms of false positive (Type I) and false negative (Type II) errors, the practice of treating an econometric result as reliable only when the confidence level is above a specified threshold-typically 90\%, 95\%, or 99\%-guards against the likelihood of committing a false positive error: erroneously rejecting the possibility that the merger will not reduce welfare. In such a world, there has to be almost no chance that the merger harms consumers. But that is not what the statute or sound policy directs. This is because by adopting this statistical stance, the probability of erroneously rejecting the alternative hypothesis that the merger will reduce welfare will grow substantial as the threshold rises-yet avoiding a false negative error is critical for adhering to the law: There is a fundamental trade-off between the two types of errors, and an exclusive focus on false positives is undesirable-both in terms of the text of the law and also from the perspective of consumer welfare.

\footnotetext{
${ }^{28}$ On behalf of the American Statistical Association, (Wasserstein and Lazar 2016), released a statement that contained six principles with regard to the use of p-values, including the following three principles: (2) P-values do not measure the probability that the studied hypothesis is true, or the probability that the data were produced by random chance alone; (5) A $p$ value, or statistical significance, does not measure the size of an effect or the importance of a result; and (6) By itself, a p-value does not provide a good measure of evidence with regard to a model or hypothesis.
} 
In our example, the solution actually is simple: The decision maker can focus on the estimate of the expected consumer welfare effect-taking both types of errors into account, with the proper weighting being based on the welfare function. If the econometrics has been done correctly, the estimate of -2.5 is an unbiased (or consistent) estimate of the expected welfare effect: It is equally likely that the true merger effect is greater or lower than -2.5. In turn, the estimate would mean that it is more likely than not that the true merger effect merger is negative and economically substantial: more negative than -2 . If the welfare function is not linear in the estimated coefficient, then the expected welfare calculation amounts to placing differential weights on false positives versus false negatives.

Kaye (1983) describes the problem as follows, where the "Alternative hypothesis" is a harmful merger that the court is attempting to learn about with the available evidence: "The more precise mathematical notation makes it plain that the burden of persuasion refers to one probability- $\operatorname{Pr}($ Alternative hypothesis: Evidence)—while the hypothesis test looks to another-Pr(Evidence: Null hypothesis)."

Because the Null hypothesis of no harm may not be true, the $\operatorname{Pr}($ Evidence: Null hypothesis) test may not be very accurate-despite being universally used. Instead, a prior is needed that takes account of all of the information that is available before the trial. More generally, balancing the two types of errors "optimally" would also depend on the strength of the other, possibly non-statistical evidence.

One possible approach would be the adoption of a Bayesian decision approach that makes use of prior information of the likely impact-based, for example, on structural presumptions, documentary evidences, or prior studies. ${ }^{29}$ For example, in the case of mergers that trigger the HHI structural presumption or another presumption, the prior distribution would be skewed towards anticompetitive effects. The agency would then update this prior distribution in the face of the econometric evidence to arrive at a new, posterior distribution. However, the Bayesian approach might be applied conceptually rather than formally because of the complexity that is involved in calculating the posterior.

In our example, if the prior is sufficiently skewed towards anticompetitive effects, the posterior may suggest that an economically substantial merger effect -2 or worse) is more likely than not, even in cases where the standard econometric estimate is greater than -2 (i.e., less negative). This can be used as the alternative hypothesis in the evaluation of Type II errors.

This analysis leads us to make several suggestions:

First, we suggest that the HMGs flag the fact that standard econometric practice tends to focus solely on false positives and explain the resulting limitations and the reasons why that approach will not be followed. ${ }^{30}$ We also recommend that the HMGs explain best practices for courts. The HMGs could discuss the different ways

\footnotetext{
${ }^{29}$ For instance, Johnson et al. (2016 pp. 658-661) presents a Bayesian decision framework in which the strength of the econometric results and the prior probability of damages -- based on the other evidence -combine to determine a posterior probability distribution for the damage amount that summarizes all the evidence and accounts for both types of errors.

${ }^{30}$ In fact, the D.C. Circuit criticized the requirement that statistical evidence satisfy the $95 \%$ confidential interval in Ethyl Corporation v. EPA, 541 F.2d 1 (D.C. Cir. 1975). See also Kaye (1983)..
} 
to take account of false negatives as well as false positives. For example, merger retrospectives of mergers that were investigated but cleared by agencies or courts (often with conditions) find, on average, positive price effects. ${ }^{31}$ Along with the structural presumption, the distribution of those price effects might constitute an appropriate prior in a statistical test. We also recommend that the agencies encourage additional research in this area to develop new methodologies.

Second, we suggest that the HMGs make clear that the agency does not require quantitative evidence to satisfy its burden for the (Step-1) prima facie case, but can rely on the structural presumption or another anticompetitive presumption. The HMGs also should make clear that if the merging parties present quantitative evidence during the HSR investigation or in court-once the burden has been shifted to them from the presumption having been triggered or other evidence- the burden to show the statistical significance of the results rests on the parties, not the agency.

Third, a complex back-and-forth between the experts can have the perverse effect of leading the judge to ignore all the econometric analysis-and, for that matter, the economic analysis - and rely instead on the self-interested testimony of the executives or the "hot documents." 32 For this reason, it would be useful for judges to have testimony on these studies by an objective court-appointed expert economist or economic consultant for the judge. ${ }^{33}$ While this is not a strict HMGs issue, perhaps the HMGs could encourage it.

\subsection{Account for a Merger's Effect on Systemic Risk}

Revised HMGs should consider taking account of the impact of mergers on welfare in the event of low probability, large exogenous shocks. ${ }^{34}$ The Covid-19 pandemic has made clear that the invisible hand may not adequately account for large exogenous shocks that create negative externalities for consumers.

For example, it appears that mergers of meat processors have left the U.S. with a small number of large plants. When workers get sick, plant closures cause large reductions in the demand for animals from farmers, as well as shortages and increased prices paid by consumers. Similarly, pharmaceutical industry mergers may have caused significant concentration in supply chains and logistics. If a shock hits a region of China and raw materials are not available from the supplier there, the resulting shortages cause more consumer harm than they would have when the second manufacturer sourced from a different place, harm that would not fall on the manufacturers.

\footnotetext{
31 Author calculations based on data from Kwoka (2014) indicate the following price effects: overall mean $=7.24 \% ; N=42$. For mergers that were cleared during Democratic administrations, mean $=6.79 \%$; $\mathrm{N}=28$; for mergers that were cleared during Republican administrations, mean $=8.14 \% ; \mathrm{N}=14$.

32 New York v. Deutsche Telekom AG, 439 F. Supp. 3d 179 (S.D.N.Y. 2020).

33 This has been done on occasion: For example, Alfred Kahn served as a consultant to the judge in the 1995 Post/Nabisco cereals merger case that involved warring econometrics by Ronald Cotterill and Daniel Rubinfeld. New York v. Kraft General Foods, Inc., 926 F. Supp. 321 (S.D.N.Y. 1995).

34 A fuller treatment of how such risk should be accounted for in merger review is laid out in Bloomfield (2020)., and the references therein.
} 
These examples motivate a general point: If scale economies lead to mergers and associated plant or logistical consolidation for each firm, then the risk of disruption-e.g., epidemic, earthquake, or nuclear power plant meltdown-will lead to a larger cost and price impact than if there were more diversity. ${ }^{35}$ The price impact also will be higher if a dramatic increase in demand bumps up against a more limited production capacity that is caused by mergers that reduce excess capacity. ${ }^{36}$ Effects in intermediate goods markets also can cascade across multiple markets, just as did the harms from the 2007-08 financial meltdown, as well as an earthquake in Japan (Boehm et al. 2019; Acemoglu et al. 2012).

This raises the question of whether merger analysis should take systematic account of the potential risks from such shocks. ${ }^{37}$ An increased potential for such harms that results from a merger should be viewed as an adverse "competitive effect." The HMGs make the point that the costs of achieving efficiencies are included in the competitive effects analysis, and this increased risk is such a cost. ${ }^{38}$

One cannot assume that firms would sufficiently account for the risks from such shocks if a substantial fraction of the effects would be externalized. For example, if positive demand shocks lead to shortages because of capacity constraints, the consequent higher prices would be passed on to consumers. Bankruptcy may partially externalize other harms. Of course, consolidation sometimes can reduce the likelihood of cascading failures, by internalizing some risks, so that offset also must be factored into the analysis.

The more difficult question is whether the potential for such shocks can be identified in advance and whether the harms are sufficiently high to make such low-probability events worth taking into account in merger analysis. The increasing interconnectedness of the international economy and the frequency of crises in the last two decades suggests that the research evidence likely exists (Baqaee and Farhi 2019), but it has not been assessed for possible inclusion in the HMGs.

\subsection{Stress the Need for Skepticism Towards the Opinions of Business Witnesses}

The HMGs refer to the fact that evidence is obtained from various sources: the merging parties, customers, and other industry participants and analysts. HMGs $\$ 2.2 .3$ expresses some skepticism with regard to the views of rivals, except where

\footnotetext{
35 For example, suppose that two mergers reduce the number of manufacturers from four high-cost firms to two low-cost firms, so that prices fall despite the increased concentration. While price levels might be only slightly lower in normal times, the impact of one plant's shutting down for an extended period of time might be much higher after the consolidation. Of course, the expected value of consumer welfare also depends on the likelihood of an extended plant shutdown.

36 Competitive markets tend to lead to more excess capacity, because the rivals need additional capacity so as to increase their shares.

37 Concern with exogenous shocks is not new. It has been recognized by merger analysts that it was risky to rely on imports to constrain price increases by concentrated domestic firms because there might be substantial changes in exchange rates or import quotas -- including quotas that are proposed by the merging firms.

38 See 2010 HMGs $\S 10$ : “Cognizable efficiencies are assessed net of costs produced by the merger or incurred in achieving those efficiencies".
} 
the competition concern is exclusionary conduct. It is surprising that the same skepticism is not expressed with respect to testimony by executives from the merging parties. The HMGs $\$ 2.2 .3$ merely state that "[t]he Agencies give careful consideration to the views of individuals whose responsibilities, expertise, and experience relating to the issues in question provide particular indicia of reliability."

New HMGs should explain in more detail the fact that unsupported claims from individuals who are employed by the merging parties that they will not raise prices, or promises that are not embedded in consent decrees or binding private contracts, should be viewed very skeptically for several reasons: First, company officers and Boards of Directors have fiduciary duties to shareholders to maximize profits (using legal strategies). If the merger creates the economic incentive for the merged firm to raise price (or reduce output, quality, or innovation), then such strategies will and must be implemented. Second, an executive may have financial or career benefits from the merger that distort his incentives or beliefs. Third, the relevant "person's" behavior in an antitrust case is the corporate person, not any particular executive. Therefore, courts should focus on the evidence that shows the incentives of the firm and testimony about those incentives - and not on contrary self-serving statements.

The opinion of the judge in the AT\&T/Time Warner vertical merger case provides an example: The judge was highly dismissive of the testimony of the cable company executives that testified against the merger. These companies were the direct customers of Time Warner and would suffer price increases for Time Warner conduct, according to the DOJ complaint, as well as being downstream competitors of AT\&T. The judge believed that there was a "threat that such testimony reflects self-interest rather than genuine concerns about harm to competition." 39 By contrast, the judge did not apply this same degree of skepticism towards the testimony of the executives of the merging firms, who did not even have these mixed motives.

The HMGs should make clear that the unit of observation in a merger review is the company, not the executive. If ordinary-course-of-business documents-written by managers "in the field" as they attempt to earn profits for their company-reveal the strategy of the company with the use of the tools that are familiar to the agencies and economists, this should be the focus of the court.

\section{Conclusions}

While the 2010 HMGs were a definite advance, experience suggests that there is more to do. We hope that our suggestions will be helpful.

Acknowledgements We would like to thank Doni Bloomfield, Tanguy Brachet, Martino DeStefano, Joe Farrell, Erik Hoverkamp, Dan Rubinfeld, Serge Moresi, Yianis Sarafidis, Carl Shapiro, Ilton Soares and John Woodbury for helpful comments on these issues. The authors regularly engage in antitrust expert witness consulting and other consulting for a range of corporations and government agencies.

${ }^{39}$ AT\&T, Inc., 916 F.3d at 92. 


\section{Appendix}

\section{References}

Acemoglu, D., Carvalho, V. M., Ozdaglar, A., \& Tahbaz-Salehi, A. (2012). The network origins of aggregate fluctuations. Econometrica, 80(5), 1977-2016.

Aryal, G., Ciliberto, F., \& Leyden, B. (2018). Public communication and collusion in the airline industry. Becker Friedman Institute, Working Paper No. 2018-11.

United States v. AT\&T, Inc., 916 F.3d 1029 (D.D.C. 2019).

Azar, J., Schmalz, M. C., \& Tecu, I. (2018). Anticompetitive effects of common ownership. The Journal of Finance, 73(4), 1513-1565.

Azar, J., Raina, S., \& Schmalz, M. C. (2019). Ultimate ownership and bank competition. Available at https://ssrn.com/abstract $=2710252$

Backus, M., Conlon, C., \& Sinkinson, M. (2018). Common ownership and competition in the ready-toeat cereal industry. Available at https://www.law.northwestern.edu/research-faculty/clbe/events/antit rust/documents/sinkinson_cereal.pdf;

Backus, M., Conlon, C., \& Sinkinson, M. (2019). the common ownership hypothesis: theory and evidence, Economic Studies at Brookings. https://www.brookings.edu/wp-content/uploads/2019/02/ ES_20190205_Common-Ownership.pdf

Baker, J. B. (2017). Market power in the US economy today. Washington Center for Equitable Growth. Retrieved from https://equitablegrowth.org/market-power-in-the-u-s-economy-today/

Baker, J. B., \& Farrell, J. (2020). Oligopoly coordination, economic analysis, and the prophylactic role of horizontal merger enforcement. Economic Analysis, and the Prophylactic Role of Horizontal Merger Enforcement (May 19, 2020), UnIV. PA, L.R.

Baker, J. B \& Scott-Morton, F. M., (2019). Confronting rising market power (Economists for Inclusive Prosperity, Policy Brief). Available at https://econfip.org/policy-brief/confronting-rising-marke t-power/

Baqaee, D. R., \& Farhi, E. (2019). The macroeconomic impact of microeconomic shocks: beyond Hulten's Theorem. Econometrica, 87(4), 1155-1203.

Barkai, S. (2016). Declining labor and capital shares (University of Chicago Stigler Center, New Working Paper Series No. 2), Available at https://ssrn.com/abstract=3489965;

Barkai, S., \& Benzell, S. G. (2018). 70 years of US corporate profits. University of Chicago Stigler Center for the Study of the Economy and the State, New Working Paper Series, 22. Available at https://research.chicagobooth.edu/stigler/research/-/media/8ee68ec563aa4c70aa94897ee04f68b6.

Bloomfield, D. (2020). Competition and risk. Available at https://papers.ssrn.com/sol3/papers.cfm?abstr act_id=3566661;

Boehm, C. E., Flaaen, A., \& Pandalai-Nayar, N. (2019). Input linkages and the transmission of shocks: Firm-level evidence from the 2011 Tōhoku earthquake. Review of Economics and Statistics, 101(1), $60-75$.

Boller, L., \& Scott-Morton, F. M., (2020). Testing the theory of common stock ownership. (Working Paper No. w27515). National Bureau of Economic Research.

Borenstein, S., \& Rose, N. L. (2014). How airline markets work...or do they? Regulatory reform in the airline industry. In N. L. Rose (Ed.), Economic regulation and its reform: What have we learned? (pp. 63-135). Chicago: University of Chicago Press.

Bush, D., \& Massa, S. (2004). Rethinking the potential competition doctrine. Wis. L. Rev., 1035.

Calvano, E., Calzolari, G., Denicolò, V., \& Pastorello, S. (2019a). Artificial intelligence, algorithmic pricing and collusion. Algorithmic Pricing and Collusion. Available at https://ssrn.com/abstract=33049 91;

Calvano, E., Calzolari, G., Denicolò, V., \& Pastorello, S. (2019b). Algorithmic pricing and collusion: What implications for competition policy? Review of Industrial Organization, 55, 255.

Ciliberto, F., \& Williams, J. W. (2014). Does multimarket contact facilitate tacit collusion? Inference on conduct parameters in the airline industry. The RAND Journal of Economics, 45(4), 764-791.

Coate, M. B., \& Ulrick, S. W. (2019). How much does the choice between the theories of collusion and unilateral effects matter in merger analysis? Available at https://papers.ssrn.com/sol3/paper s.cfm?abstract_id=2995679 
Cunningham, C., Ederer, F., \& Ma, S. (2019). Killer acquisitions. Available at SSRN. http://dx.doi. org/10.2139/ssrn.3241707

Cutler, D. M., \& Scott-Morton, F. M. (2013). Hospitals market share, and consolidation. The Journal of the American Medical Association, 310, 1964.

Dafny, L., Ho, K., \& Lee, R. S. (2016). The price effects of cross-market hospital mergers (Working Paper No. w22106). National Bureau of Economic Research.

Ethyl Corporation v. EPA, 541 F.2d 1 (D.C. Cir. 1975)

Fed. Trade Comm'n \& U.S. Dep't of Justice, (2019), Hart-Scott-Rodino Annual Report Fiscal Year $201822 \&$ n.2. Available at https://www.ftc.gov/system/files/documents/reports/federal-trade -commission-bureau-competition-department-justice-antitrust-division-hart-scott-rodino/fy18hsrrep ort.pdf

Federal Trade Commission v. RAG-Stiftung et. al., No. 19-2337, 2020 U.S. Dist. LEXIS 18346 (D.D.C. Feb. 3, 2020)

Federal Trade Commission v. Steris Corp., 133 F. Supp. 3d 962 (N.D. Ohio 2015).

Gans, J., Leigh, A., Schmalz, M., \& Triggs, A. (2019). Inequality and market concentration, when shareholding is more skewed than consumption. Oxford Review of Economic Policy, 35(3), $550-563$.

Gaynor, M., \& Town, R. (2012). The impact of hospital consolidation-update. The Synthesis Project. Robert Wood Johnson Foundation. Available at http://www.rwjf.org/en/library/research/2012/06/ the-impact-of-hospital-consolidation.html

Gerakos, J., \& Xie, J. (2019). institutional horizontal shareholdings and generic entry in the pharmaceutical industry. Tuck School of Business Working Paper, (3285161). Available at https://ssrn. com/abstract $=3285161$

Goolsbee, A. \& Syverson, C. (2019). Monopsony power in higher education: A tale of two tracks, NBER, Working Paper No. 26070. Retrieved Nov 29, 2020 from https://www.nber.org/papers/ w26070.pdf;

Harrington, J. E., Jr. (2013). Evaluating mergers for coordinated effects and the role of parallel accommodating conduct. Antitrust LJ, 78, 651.

Hausman, J., Moresi, S., \& Rainey, M. (2011). Unilateral effects of mergers with general linear demand. Economic Letters, 111(2), 119-121.

Heim, S., Hüschelrath, K., Laitenberger, U., \& Spiegel, Y. (2019). The anticompetitive effect of minority share acquisitions: Evidence from the introduction of National Leniency Programs. Working Paper. Available at https://www.tau.ac.il/ spiegel/papers/MS-20190412.pdf.

In Re B.A.T. Industries, 104 F.T.C. 852, 926 (1984)

Institute for Mergers, Acquisitions and Alliances, (2020). Announced M\&A in the United States by numbers and value by years. Available at https://imaa-institute.org/m-and-a-us-united-states/.

Johnson, P., Leamer, E., \& Leitzinger, J. (2016). Statistical significance and statistical error in antitrust analysis. Antitrust L.J., 81, 641.

Joint Response to the House Judiciary Committee on the State of Antitrust Law and Implications for Protecting Competition in Digital Markets (April 30, 2020), https://equitablegrowth.org/wp-content/ uploads/2020/04/Joint-Response-to-the-House-Judiciary-Committee-on-the-State-of-Antitrust-Lawand-Implications-for-Protecting-Competition-in-Digital-Markets.pdf.

Kaye, D. H. (1983). Statistical significance and the burden of persuasion. Law \& Contemp. Problems, 46, 13.

Kleiman, M., \& Kilmer, B. (2009). The dynamics of deterrence. Proceedings of the National Academy of Sciences, 106(34), 14230-14235.

Kreuger, A. \& Ashenfelter, O. (2018). Theory and evidence on employer collusion in the Franchise sector, NBER, Working Paper. Retrieved Nov 29, 2020 from https:/www.nber.org/papers/w24831.

Kwoka, J. (2014). Mergers, merger control, and remedies: A retrospective analysis of U.S. policy. : Cambridge: MIT Press.

Miller, N. H., \& Weinberg, M. C. (2017). Understanding the price effects of the MillerCoors joint venture. Econometrica, 85(6), 1763-1791.

Miller, N., Sheu, G., \& Weinberg, M. C. (2019). Oligopolistic price leadership and mergers: The United States Beer Industry. Available at https://ssrn.com/abstract=3239248.

New York v. Kraft General Foods, Inc., 926 F. Supp. 321 (S. Dist. NY 1995)

Newham, M., Seldeslachts, J., \& Banal-Estanol, A. (2018). Common Ownership and Market Entry: Evidence from Pharmaceutical Industry. Retrieved from https://www.diw.de/documents/publikatio nen/73/diw_01.c.591375.de/dp1738.pdf 
Nocke, V., \& Whinston, M. D. (2020). Concentration screens for horizontal mergers (No. w27533). National Bureau of Economic Research.

Prager, E., \& Schmitt, M. (2019). Employer consolidation and wages: Evidence from hospitals. Washington Center for Equitable Growth Working Paper. Available at https://ssrn.com/abstract=3391889;

Rose, N. L., \& Sallet, J. (2020). The Dichotomous Treatment of Efficiencies in Horizontal Mergers: Too Much? Too Little? Getting it Right. UnIV. PA. L.R., Forthcoming.

Royall, M. S., \& Di Vincenzo, A. J. (2010). Evaluating mergers between potential competitors under the new horizontal merger guidelines. Antitrust, 25, 33.

Rubinfeld, D. L. (1985). Econometrics in the courtroom. Columbia L.R, 85(5), 1048-1097.

Sabbatini, P. (2016). The coordinated effect of a merger with balanced sharing of collusive profits. Journal of Industry, Competition and Trade, 16(3), 345-371.

Salop, S. C., \& Moresi, S. (2009). Updating the merger guidelines: Comments. Available at https:// loadtest.ftc.gov/sites/default/files/documents/public_comments/horizontal-merger-guidelines-revie w-project-545095-00032/545095-00032.pdf;

Scott-Morton, F. M., (2019). Modern U.S. antitrust theory and evidence amid rising concerns of market power and its effects. Washington Center for Equitable Growth. https://equitablegrowth.org/resea rch-paper/modern-u-s-antitrust-theory-and-evidence-amid-rising-concerns-of-market-power-andits-effects/;

Shapiro, C. (2018). Update from the antitrust division. Retrieved from https://www.justice.gov/atr/ file/518246/download.

State of New York v. Deutsche Telekom AG, No. 1:19-cv-05434-VM-RWL (S.Dist. NY, 2020)

TC v. Steris Corp., 133 F. Supp. 3d 962 (N.D. Ohio 2015)

United States v. Baker Hughes, Inc., 908 F.2d 981, 991 (D.C. Cir. 1990).

United States v. Sabre Corp., No. 19-1548-LPS, 2020 U.S. Dist. LEXIS 64637 (D. Del. Apr. 7, 2020).

U.S. Dep't of Justice, Appropriation Figures for the Antitrust Division Fiscal Years 1903-2021 (2020). https://www.justice.gov/atr/appropriation-figures-antitrust-division

Wasserstein, R. L., \& Lazar, N. A. (2016). The ASA Statement on p-Values: Context, Process, and Purpose 70 The American Statistician 129. Available at https://amstat.tandfonline.com/doi/ full/10.1080/00031305.2016.1154108

Publisher's Note Springer Nature remains neutral with regard to jurisdictional claims in published maps and institutional affiliations. 